\title{
Correction to: Population Grids for Analysing Long-Term Change in Ethnic Diversity and Segregation
}

\author{
Gemma Catney ${ }^{1}$ (1) $\cdot$ Christopher D. Lloyd ${ }^{1}$ (1)
}

Accepted: 8 January 2021 / Published online: 8 February 2021

(c) Springer Nature Switzerland AG 2021

\section{Correction to: Spatial Demography https://doi.org/10.1007/s40980-020-00071-6}

At production stage, a misunderstanding about the presentation of Table $1 \mathrm{~b}$ occurred. The corrected Table 1 is given below.

The original article has been corrected.

The legends and part figure descriptors of figures 1 and 2 are placed under the first part ('a') of the relevant figures as per Springer style.

The original article can be found online at https://doi.org/10.1007/s40980-020-00071-6.

Gemma Catney

g.catney@qub.ac.uk

1 Queen's University Belfast, Geography, School of Natural And Built Environment, Belfast BT7 1NN, UK 


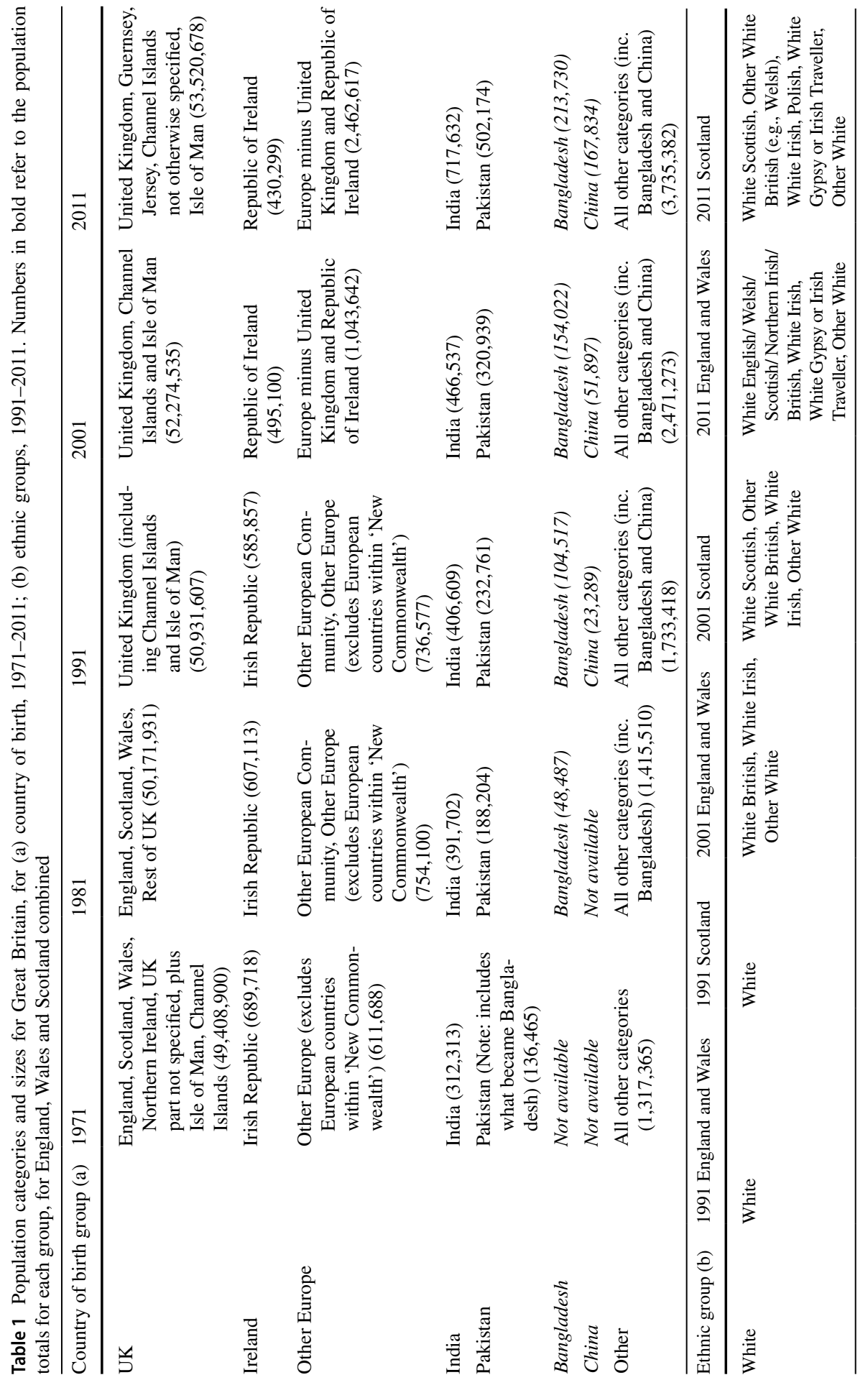




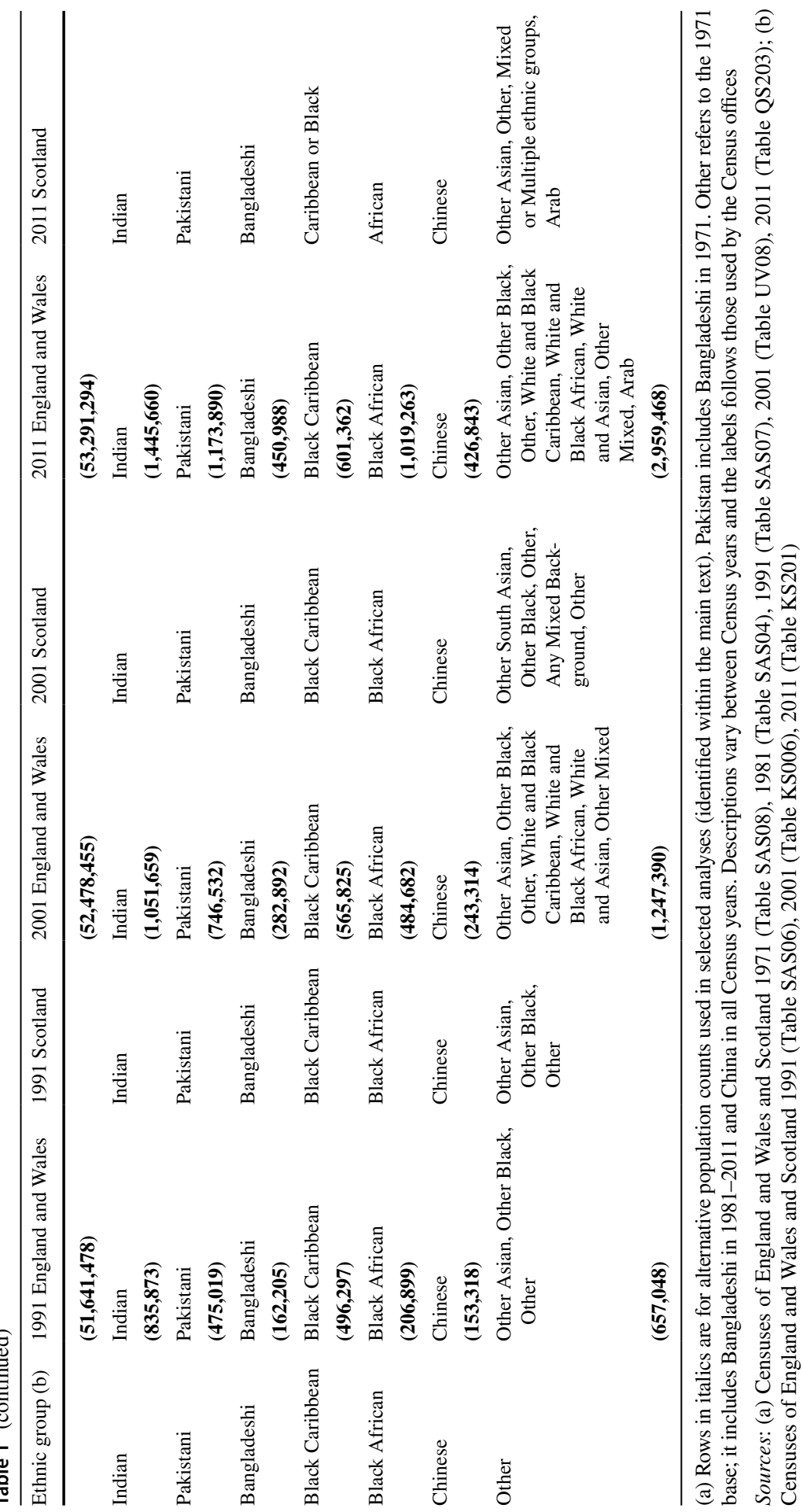


Publisher's Note Springer Nature remains neutral with regard to jurisdictional claims in published maps and institutional affiliations. 